\title{
Expanded carrier screening: what determines intended participation and can this be influenced by message framing and narrative information?
}

\author{
Jan S Voorwinden ${ }^{\star, 1}$, Anne H Buitenhuis ${ }^{1}$, Erwin Birnie ${ }^{2}$, Anneke M Lucassen ${ }^{3}$, Marian A Verkerk ${ }^{4}$, \\ Irene $\mathrm{M}$ van Langen ${ }^{2}$, Mirjam Plantinga ${ }^{2}$ and Adelita V Ranchor ${ }^{1}$
}

Next-generation sequencing enabled us to create a population-based expanded carrier screening (ECS) test that simultaneously tests for $\mathbf{5 0}$ serious autosomal recessive diseases. Before offering this test universally, we wanted to know what factors are related to intended participation and how the general public can be informed about the test without being influenced in their intention to participate. We studied this by measuring to what extent 'message framing' and 'narrative information' can influence people's intended participation. Data were collected by means of an online survey of 504 potential users, and the factors examined were based on the Theory of Planned Behaviour and on previous research on intended participation in preconception carrier screening. Message framing was manipulated by explaining the risk of couple carriership in different ways, while narrative information was provided to only half of the respondents. The factors most positively related to intended participation were perceiving benefits of the screening, having a positive attitude towards the screening, having no religion, having an actual child wish and experiencing the choice to participate as easy. Perceived benefits and a positive attitude were most influential factors by far. Message framing and narrative information had no significant effect on intended participation, reinforcing that message framing and narrative information can help to inform the general public about ECS without influencing their intended participation. Future research should study if the importance of perceived benefits and a positive attitude can be replicated when other factors are included and when actual participation is measured instead of intended participation.

European Journal of Human Genetics (2017) 25, 793-800; doi:10.1038/ejhg.2017.74; published online 3 May 2017

\section{INTRODUCTION}

Approximately 1-2 in 100 couples are at risk of having a child affected with a recessive genetic condition. ${ }^{1}$ Population based expanded carrier screening (ECS) makes it possible to test couples before pregnancy for relevant recessive genetic conditions simultaneously. The preconception period might be considered a better time than the prenatal period, because it results in more reproductive options being available and termination of pregnancy can be avoided. ${ }^{2}$

Next-generation sequencing techniques enabled us to create such a population-based ECS test that simultaneously tests for 50 serious autosomal recessive diseases. ${ }^{3}$ The composition of this panel was based on previous research, multidisciplinary discussions and stakeholder meetings. Screening results are couple-based, so only couples who are both carriers of the same disease get positive results. However, before this test can be offered in a public healthcare setting, we needed a better understanding of the factors driving intended participation and how the general public could be better informed-but not influenced -in their intention to participate. This information is important because it is clear from previous research and clinical practice that risk information is difficult to understand and people may interpret it differently. ${ }^{4-7}$

The factors that we examine are based on the Theory of Planned Behaviour (TPB), on previous research on intended participation in preconception carrier screening (PCS) and two new factors. The TPB was chosen because it has proven to be a useful framework in explaining and predicting health behaviour. ${ }^{8}$ Most research in the past was based on factors from the health belief model, ${ }^{9}$ which are also included here because they are part of the previous research on intended participation in PCS. By adding the factors from the TPB, we hope to reach a more comprehensive understanding of the most important factors driving intended participation in ECS. According to the TPB, participation is explained by intention, which in turn is explained by personal attitude towards the test, subjective norm (how much influence the opinion of others has on an individual) and perceived behavioural control (how easy people experience the choice to participate). ${ }^{10}$ Only one study thus far has examined the influence of factors from the TPB on intended participation in PCS for two prevalent diseases, cystic fibrosis and haemoglobinopathies. ${ }^{11}$ Having a positive attitude towards PCS, experiencing the choice to participate as easy and perceiving more influence of a partner's opinion towards participation were related to more intention to participate. ${ }^{11}$ In our research we examine if these TPB factors are also related to intended participation in ECS.

In addition to the TPB factors, we also examine other factors that were identified in previous research on intended participation in PCS. A systematic review found that the factors most frequently significantly

\footnotetext{
${ }^{1}$ Department of Health Psychology, University Medical Center Groningen, University of Groningen, Groningen, The Netherlands; ${ }^{2}$ Department of Genetics, University Medical Center Groningen, University of Groningen, Groningen, The Netherlands; ${ }^{3}$ Department of Clinical Ethics and Law, Faculty of Medicine, University of Southampton, Southampton, UK; ${ }^{4}$ Department of Internal Medicine, University Medical Center Groningen, University of Groningen, Groningen, The Netherlands

${ }^{*}$ Correspondence: Dr JS Voorwinden, Department of Health Psychology,University Medical Center Groningen, Hanzeplein 1, P.O. Box 30001, Groningen 9700 RB, The Netherlands. Tel: +31 503613 885; E-mail: j.s.voorwinden@umcg.nl

Received 18 November 2016; revised 10 March 2017; accepted 5 April 2017; published online 3 May 2017
} 
related to intended participation in PCS were perceiving more benefits of undergoing screening, perceiving fewer barriers to undergoing screening and having few or no children. ${ }^{12}$ Less frequent significantly related factors were having a higher educational level, perceiving more susceptibility of being a carrier, having more disease-related knowledge, being female and perceiving more severity of being a carrier. ${ }^{12}$ The studies that were included in this systematic review were only focused on intended participation in cystic fibrosis carrier testing. These factors were also mentioned in more recent studies and preconception carrier testing for other type of diseases. ${ }^{13,14}$ However, it is still unknown if these factors will also be related to intended participation in ECS.

Two new factors are studied in this research: religion and having an actual child wish. The influence of these factors on intended participation in preconception screening is unknown, but they were included because of their supposed relevance in predicting intended participation in ECS. Having an actual child wish could be related to more intended participation because ECS becomes more relevant in comparison to participants without such a child wish. Following a religion could be related to less interest for ECS because of having more objections towards medical procedures that influence pregnancy and birth. Following a religion has been associated with less uptake in prenatal screening. ${ }^{15,16}$ The aim of this study is to understand the influence of all these factors (from the TPB, previous research based on the health belief model, and the two new factors) on intended participation in ECS.

How the general public can be informed-but not influenced-in their intention to participate in ECS, was studied by measuring to what extent 'message framing' and 'narrative information' can influence people's intended participation. In reproductive counselling framing is important because the aim of non-directivity. To avoid the impact of framing on intended participation, information is often framed double: by presenting the chance of being a carrier couple and presenting the chance of not being a carrier couple. This type of framing is known as attribution framing. ${ }^{17,18}$ Attribution framing assumes that mentioning the chance of staying healthy leads to a more positive judgment than mentioning the risk of having a disease, while the actual chance of being affected is the same. The effect of attribution framing has been studied in healthcare decisions. In a systematic review, attribution framing appeared to have some effect on comprehension and perception of effectiveness, but not on participation and health behaviour. ${ }^{19}$ The conclusion of this review was that the impact of attribution framing is low in healthcare. However, their recommendation was that attribution framing should be investigated in more natural settings, as many studies were based on hypothetical situations and were presented to students. On the basis of these outcomes, we expect the effect of negative framing (mentioning the risk of couple carriership) in comparison to positive framing (mentioning the chance of couple non-carriership) will not be large enough to significantly influence intention to participate in ECS. However, negative framing could lead to significantly more perceived susceptibility of being a carrier couple. When the risk of being a carrier couple is emphasized, people are expected to experience more threat than they would when the chance of not being carriers of the same disease is emphasized.

Another issue is the amount and type of information about ECS that the general public should receive in order to be able to make an informed choice. Narrative information is sometimes added to factual information to increase understanding about the consequences of having to raise a child with a genetic disease. It is therefore necessary to understand if adding narrative information can also change intention to participate in ECS. Several systematic reviews have shown that adding narrative information influences decision-making, by making decisions more experiential-automatic (emotional) than analytic-deliberative (rational) ${ }^{20,21}$ although the possibility to measure emotional and rational decisions independently can be discussed because of their interrelatedness. Because the amount and type of narrative information varies greatly between studies, it is still difficult to determine which aspects of narrative information have the most influence on emotions and in what way narrative information is related to intended participation. ${ }^{21}$ Because the effect of narrative information on intended participation is unclear, we do not expect that the effect of including narrative information will be strong enough to significantly change intended participation in ECS. However, because of the possible influence of narrative information on emotions, we expect that adding narrative information will increase the emotional impact of the information about ECS, leading to more perceived severity of having a child with a serious genetic disease.

To summarize, our research considers two questions:

1. What factors are significantly related to intended participation in ECS? Factors that are studied are from the TPB, from earlier research about intended participation in PCS and two new factors: religion and having an actual child wish.

2. What is the influence of message framing and narrative information on intended participation, perceived susceptibility and perceived severity in well informed respondents? While we do not expect that message framing and adding narrative information will significantly influence intended participation, we do expect that only mentioning the risk of carriership will lead to significantly more perceived susceptibility of being a carrier couple in comparison to mentioning only the risk of non-carriership. Also that including narrative information to factual information will lead to significantly more perceived severity of having a child with a serious genetic disease in comparison to excluding narrative information.

\section{MATERIALS AND METHODS}

\section{Respondents}

Potential respondents, both men and women with a partner and of reproductive age (18-40 years), were recruited in the Netherlands via an existing panel of an international company specialized in sampling for marketing and academic research in March $2014 .^{22}$ We have chosen this age range because an actual child wish is expected to be most frequent during this period among men and women. Data from 504 potential users were collected three times using online questionnaires. To award the time respondents spent participating in the study, the company offered an incentive in reward points up to a maximum value of $€ 2.50$ that could be redeemed in a web-shop. Ethical clearance for this study was granted by the Medical Ethical Review Committee of the University Medical Center Groningen (M14.152635).

\section{Study design}

Figure 1 shows the study design. First, respondents received online factual information about ECS with an explanation of the purpose of ECS, of how ECS is carried out and of the study goal to understand the opinion of respondents about ECS. After reviewing this information, respondents had to complete questionnaire T0. Respondents then received additional online factual information about ECS consisting of a summary of the previous information, the manipulations and an explanation of the reproductive options in case of couple carriership. The manipulations consisted of message framing (positive or negative framing of risks) and narrative information (included or excluded narrative information about one of the diseases). A complete overview of the primary and additional information that was given to respondents can be found in the Supplementary Information. Directly after receiving the additional information, respondents had to complete questionnaire T1. After T1, respondents were asked to discuss their opinion about ECS with their partner. 


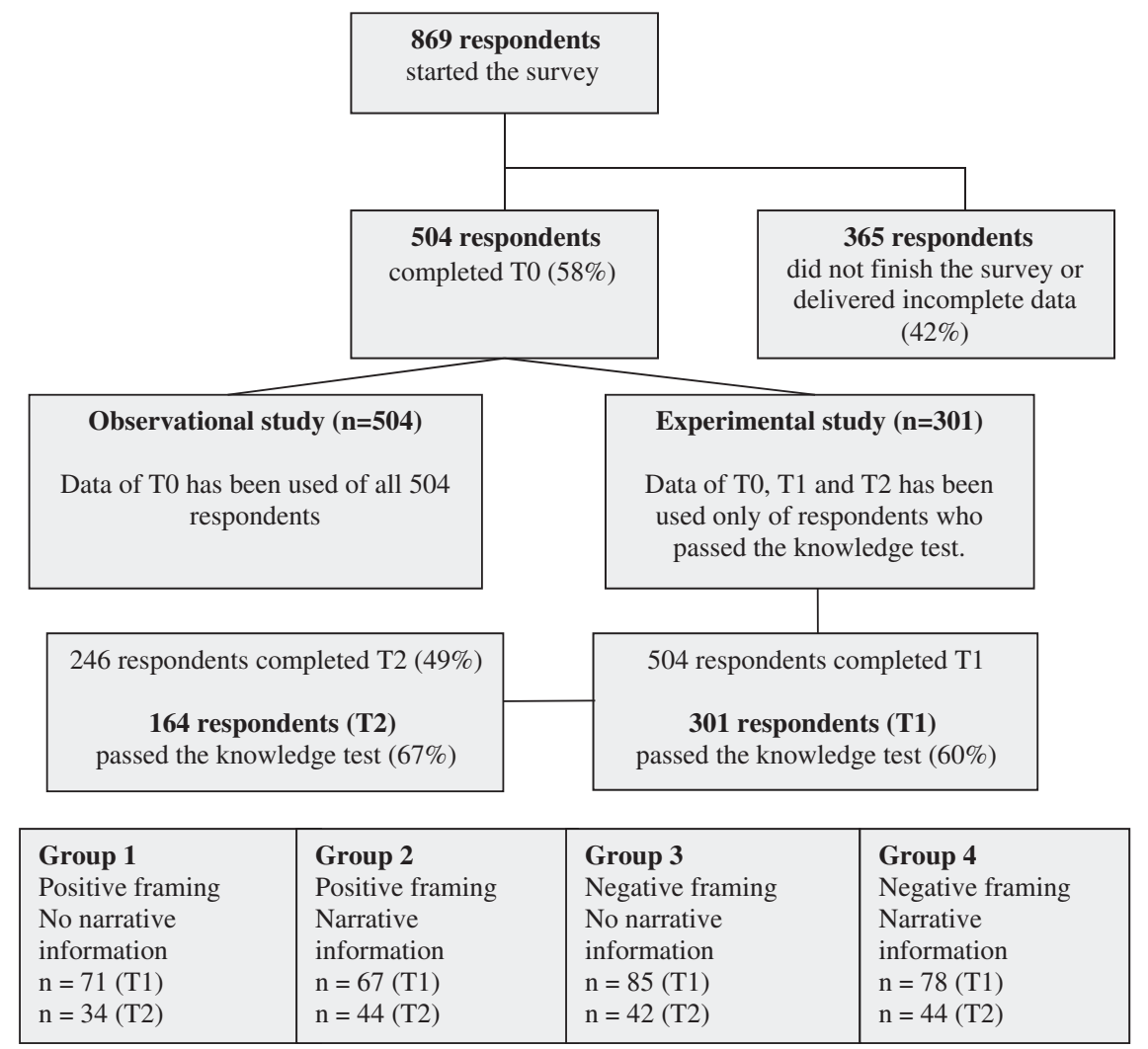

Figure 1 Flow chart of the study design.

Questionnaire T2 was offered two weeks later. Responses of partners were not used in this study. T0 and T1 were completed individually by respondents. Partners of respondents were only involved after T1.

To address our first research question considering what factors are related to intended participation, we used the data from $\mathrm{T} 0$ from all the respondents. To address our second research question considering the influence of message framing and narrative information on intended participation, perceived susceptibility and perceived severity, we used the data from T0, T1 and T2. T0 was used as a pre-experimental measurement to check if there were no differences in the outcome variables between the groups before the manipulations were offered. The effect of the manipulations was measured on T1 and T2. We used two measurements to check if the effect of the manipulations remained constant in time. As the manipulations were offered together, interaction effects between message framing and narrative information were also measured. To measure the effect of the manipulations, it was necessary that respondents understood the information sufficiently. Otherwise it remains unknown if the presence or absence of an effect of the manipulations is due to lack of understanding or if it is due to how information was presented. Therefore, in the experimental study we only included respondents who passed a knowledge test about ECS in order to exclude respondents who had not read the information about ECS well enough or who had not understood it. Eligible respondents were allocated randomly across four groups.

\section{Manipulations}

Message framing. In the negative framing condition, the risk of being a carrier couple of one of the 50 serious hereditary diseases was given as ' $1 \%$ or 1 in 100'. In the positive framing condition, the chance of not being a carrier couple of the same diseases was given as ' $99 \%$ or 99 in 100 '.

Narrative information. Half of the respondents received the following narrative information: An example of a disease being tested is Epidermolysis Bullosa (EB). EB is a very serious skin disease where a baby has blisters all over the body from birth. Children with EB are also known as butterfly children. Their skin is as thin and fragile as the wings of a butterfly. If children with EB fall or stumble, the skin becomes damaged on the spot that has been touched. Changing the bandage on the affected skin requires daily care and is very painful. To disinfect the blisters patients with $\mathrm{EB}$ have to lay regularly in a bath with chlorine for $1-2 \mathrm{~h}$. The scars of the blisters may lead to deformities, especially of the feet. Most children with EB live no longer than two years.

\section{Measurement instruments}

A complete overview of all the items and answer options of the different measurement instruments can be found in the Supplementary Information. A short description of the measurement instruments is presented here.

Knowledge test. The knowledge test consisted of nine self-constructed multiple-choice questions based on the factual information about ECS that respondents had to read. Four questions were about which diseases the ECS test covers, two were about risk percentages and three were about the possibility of different reproductive options in case of couple carriership. The total score could range from 0 to 9. A higher score indicated more knowledge about ECS. The internal consistency of the knowledge test was good for this sample (Cronbach's $\alpha 0.81$ ). Respondents had to answer more than $2 / 3$ of the questions correctly (a minimum score of 7) to consider the factual information about ECS sufficiently understood.

Intention to participate, perceived behavioural control, attitude towards the screening and subjective norm. These scales were based on the TPB framework and previous research that used the TPB concepts to study intended participation in prenatal screening. ${ }^{10,23}$ Intention to participate was measured with two items asking respondents if they 'would consider' and 'would be willing' to participate in ECS on a 7-point scale (1-7). The total score could therefore range from 2 to 14, with a higher score indicative of more intention to participate in ECS. The internal consistency of the intention to participate scale in our sample was good (Cronbach's $\alpha$ 0.95, 0.96 and 0.96 for T0, T1 and T2, respectively). Perceived behavioural control was measured with one item considering how easy respondents experienced the choice to participate in ECS on a 5-point scale (1-5), with a higher score indicative of experiencing the 
choice as easier. Attitude towards the screening was measured with one item considering the first reaction of respondents about ECS on a 7-point scale (1-7), with a higher score indicative of a more positive attitude. Subjective norm was measured with three items on a 5-point scale. Respondents were asked how much influence they experienced of the opinions of their partner, family and friends in their intention to participate in ECS. Because of low internal consistency (Cronbach's $\alpha$ 0.58), the item about the opinion of the partner was analysed separately. This item has a scoring range of $1-5$. The influence of the opinion of family and friends was measured with two items with a scoring range of 2-10. Higher scores meant more influence of the opinion of others for both scales. The internal consistency of the two family and friends items was good (Cronbach's $\alpha$ 0.86).

Perceived severity, susceptibility, benefits and barriers. These scales were based on previous research, where factors related to intended participation in PCS for cystic fibrosis were studied. ${ }^{24}$ Perceived severity was measured with four items on a 5-point scale (4-20). Respondents were asked how disturbing it would be to have a child with either severe pain, severe physical disability or severe intellectual disability, or who would die at a young age. A higher score was indicative of more perceived severity of having an affected child. The internal consistency of the perceived severity scale was good (Cronbach's $\alpha 0.87,0.88$ and 0.89 for T0, T1 and T2, respectively). Perceived susceptibility was measured with two items on a 5-point scale (2-10). Respondents were asked how they estimate 'the chance of being a carrier couple of one of the diseases' and 'the chance to have a child with a disease from the carrier couple test'. A higher score was indicative of more perceived susceptibility. The internal consistency was good (Cronbach's $\alpha$ 0.88, 0.88 and 0.94 for T0, T1 and T2, respectively). Perceived benefits were measured with five items on a 5-point scale (5-25). Respondents were asked how they perceived different possible benefits of participating in ECS. An example of one item is 'ECS gives me more certainty about the decision to have children'. A higher score was indicative of perceiving more benefits about the screening. The internal consistency was good (Cronbach's $\alpha$ 0.83). Perceived barriers were measured with three items on a 5-point scale. Respondents were asked 'if ECS would lead to worries about the test result', 'if they would feel less healthy if they both appear carriers of the same disease' and 'if people would look differently at them if they both appear carriers of the same disease' (score range 1-5). Because these items had a low internal consistency (Cronbach's $\alpha$ 0.50), they were analysed separately. A higher score was indicative of perceiving a higher barrier towards the screening.

\section{Statistical analysis}

For the first research question all the factors were entered individually into a univariate regression analysis to determine whether there was a significant relationship with intention to participate. Only variables with a $P$-value of $\leq 0.10$ were included into a multiple linear regression analysis, for which a forced entry measure has been used. Which variables in the multiple regression model were most influential, was based on the size of the standardized beta values (a bigger absolute value means more importance). The predictive value of the final model was determined by the percentage of explained variance adjusted for shrinkage. For the second research question, demographic variables were compared between the 301 respondents versus the 184 respondents that were excluded due to insufficient knowledge about ECS. The pre-experimental scores (T0) of the demographic and outcome variables were compared between respondents of the different groups. We used the chi-square test for the demographic data and the one-way independent ANOVA for age and the outcome variables. Demographic variables were also compared between the 164 respondents of T2 and the 137 drop-outs after T1. Intention to participate was compared between the different groups on $\mathrm{T} 1$ and $\mathrm{T} 2$ with a $2 \times 2$ ANOVA factorial design. Perceived susceptibility and perceived severity were compared with a $T$-test for independent samples. Differences between the manipulations were checked for statistical significance $(P<0.05)$ and effect sizes (Cohen's $d$ ). An effect size of 0.2 is considered small, 0.5 is medium and 0.8 is large. All statistical analyses were carried out with IBM SPSS Statistics 22 .

\section{RESULTS}

\section{Respondents}

Figure 1 shows the number of respondents in the study.

\section{Research question 1: What factors are most related to intended participation in ECS?}

In the univariate regression analysis factors with a significant relationship with intention to participate were: attitude towards ECS, subjective norm (partner), subjective norm (other people), behavioural control, perceived benefits of ECS, perceived barrier to ECS (worry), perceived susceptibility of being a carrier, knowledge about ECS, gender, perceived severity of having a child with a serious genetic disease, religion and having an actual child wish. Table 1 shows that attitude towards ECS and perceived benefits of ECS were the most influential factors (standardized betas of 0.47 and 0.59 respectively).

Second, a multiple linear regression analysis was carried out that showed that intended participation is best predicted by more perceived benefits of ECS, a more positive attitude towards ECS, no religion, an actual child wish and more behavioural control (see Table 2). Together these factors explain $45 \%$ of the total variance. Perceived benefits and a positive attitude towards ECS were the most influential factors (standardized betas of 0.47 and 0.22 , respectively).

Research question 2: What is the influence of message framing and narrative information on intended participation, perceived susceptibility and perceived severity in well informed respondents? Pre-experimental measurement. There were no significant differences in demographic and outcome variables between the four groups in the pre-experimental measurement (Table 3). Of the 504 respondents, 203 (40\%) did not pass the knowledge test and were therefore excluded from the analysis of the second research question. Significantly more women passed the knowledge test in comparison to men (68 vs $46 \%$, $\left.\chi^{2}(1)=19.35, P<0.001\right)$. Educational level was significantly related to knowledge $\left(\chi^{2}(2)=13.76, P=0.001\right)$, and more highly educated respondents passed the test $(73 \%)$ than respondents with low $(61 \%)$ and intermediate (53\%) levels of education.

Drop-outs in the follow-up (T2). Of the 301 respondents, 164 completed T2 (54\%) and 137 dropped out after T1 (46\%). More highly educated respondents completed T2 $(63 \%)$ in comparison to respondents with intermediate (47\%) and low (51\%) levels of education $\left(\chi^{2}(2)=6.13, P=0.047\right)$. Significantly more women completed T2 in comparison to men (58vs $\left.41 \%, \chi^{2}(1)=5.62, P=0.018\right)$. The type of relationship was significantly related to drop-out in the follow-up $\left(\chi^{2}(2)=8.49, P=0.014\right)$; more married respondents completed T2 $(66 \%)$ in comparison to unmarried respondents living apart $(50 \%)$ or living together $(48 \%)$ with their partner.

The influence of message framing and narrative information on intended participation, perceived susceptibility and perceived severity. Results are shown in Table 4. Message framing and narrative information had no significant effect on intention to participate immediately after the manipulations (T1) and two weeks later (T2) after discussion between respondents and partners. There were also no significant interaction effects between message framing and narrative information on intention to participate. Negative framing (mentioning the risk of couple carriership) had no significant effect on perceived susceptibility in comparison to positive framing (mentioning the chance of couple non-carriership). Moreover, inclusion of narrative information had no significant effect on perceived severity of having an child with a serious genetic disease in comparison to excluding narrative information. 
Table 1 Univariate linear regression analysis

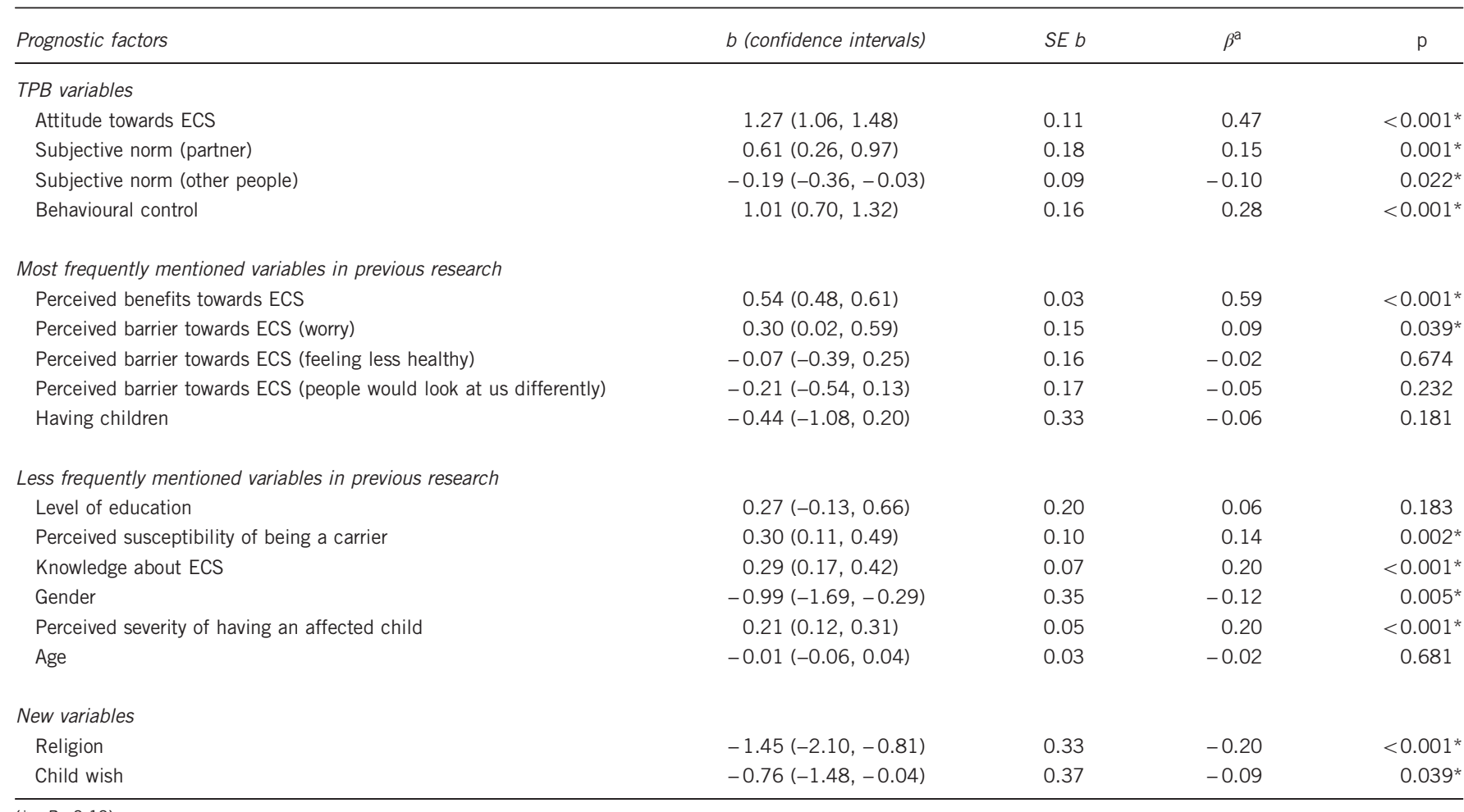

$(*=P \leq 0.10)$.

astandardized regression coefficient.

Table 2 Multiple linear regression analysis

\begin{tabular}{lcccc}
\hline Prognostic factors & $b$ (confidence intervals) & SE $b$ & \multicolumn{1}{c}{$\beta$} & \multicolumn{1}{c}{$\mathrm{p}$} \\
\hline Perceived benefits towards ECS & $0.43(0.36,0.51)$ & 0.04 & 0.47 & $<0.001^{*}$ \\
Attitude towards ECS & $0.60(0.38,0.83)$ & 0.11 & 0.22 & $<0.001^{*}$ \\
Religion & $-0.84(-1.37,-0.32)$ & 0.27 & -0.11 & $0.002^{*}$ \\
Child wish & $-0.88(-1.45,-0.31)$ & 0.29 & -0.11 & $0.003^{*}$ \\
Behavioural control & $0.36(0.08,0.65)$ & 0.15 & 0.10 & $0.013^{*}$ \\
\hline
\end{tabular}

(Adjusted $R^{2}=0.45 ;{ }^{*}=P<0.05$ ).

\section{DISCUSSION}

This is the first research that clarifies which factors seem to be most related to intended participation in ECS. In particular, we found that message framing and narrative information could inform the general public about ECS without influencing their intended participation.

Factors most related to intended participation in ECS were perceiving more personal benefits of the screening, having a more positive attitude towards the screening, not being religious, having an actual child wish and experiencing the choice to participate as easy. These factors together explained $45 \%$ of the variance in our study. Perceived benefits and a positive attitude towards the screening appear to be the strongest explanatory factors by far. The importance of perceived benefits is in line with other research. ${ }^{12,24}$ The importance of a positive attitude towards the screening is, although not unexpected, a relatively new finding as the influence of TPB factors on intended participation in PCS has been studied only once before. ${ }^{11}$ Our multivariable analysis shows that these two factors independently explain a considerable amount of the variance of intended participation in ECS. Future research aimed at improving informed choice, should study if the importance of perceived benefits and a positive attitude can be replicated when other factors are included, and when actual participation is measured instead of intended participation. The better and the more 'personalized' respondents are informed about ECS, the easier it is for them to form attitudes about the test that correspond to their own norms and values. After knowing which factors are most related to intended participation, a next step would be to optimize the content of pre-test information about ECS and to tailor this information to the eligible couples, for instance by a digital decision aid.

In line with our expectations, message framing and narrative information were not related to intention to participate. Contrary to our expectations, message framing had no influence on perceived susceptibility of being a carrier couple. An explanation for this could be that most respondents experienced the risk of being a carrier couple, as low in the pre-test analysis. If respondents experience such low risk, then the effect of message framing seems not powerful enough to change such a perception. Practically speaking, it is unnecessary to frame risk information about couple carriership in a double way, if this double-framing is based on the assumption that one type of framing could influence intended participation or perceived susceptibility.

Also, unexpectedly, adding narrative information did not influence the perceived severity of having an affected child. This lack of effect may be due to a ceiling effect: many respondents in the pre-test experimental analysis already experienced a very strong negative attitude towards having a child with one of the 50 diseases. As a consequence, narrative information could not increase perceived severity much. That narrative information seems not to change intended participation implies that narrative information can be 
Table 3 Pre-test analysis

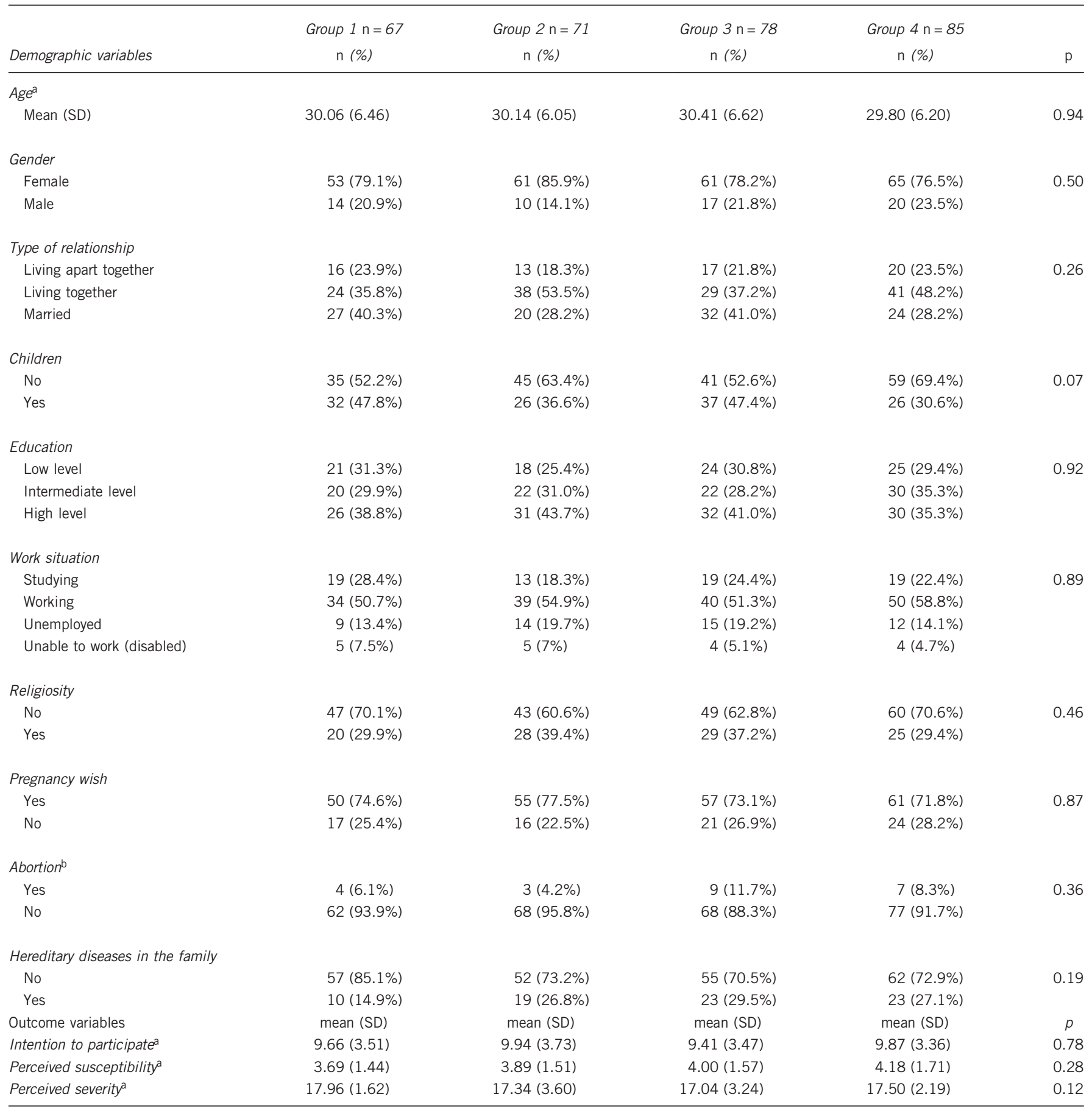

(Group 1 = positive framing and no narrative information; Group 2 = positive framing and narrative information; Group 3 =negative framing and no narrative information; Group 4 = negative framing and narrative information).

amean and SD are given instead of number and percentage.

amean and $\mathrm{SD}$ are given instead
bthis variable has missing values.

included in information about ECS to increase understanding of the consequences of having to raise a child with a genetic disease.

Strengths of this research are its experimental design, the large number of measurements, the heterogeneous study population and the large number of respondents. The research sample is representative, as it consisted of both men and women, all of reproductive age and having a partner. This is exactly the population for who the choice to participate in ECS is most relevant. A major strength is that so many potential associated variables were comprehensively examined and that two different manipulations were studied.

A limitation of this research is the focus on intended participation instead of actual participation. Although intended participation has a moderate to major influence on actual participation in other studies, these concepts are not entirely similar, especially when the time 
Table 4 Results of the experimental study

\begin{tabular}{|c|c|c|c|c|c|c|c|c|}
\hline \multirow[t]{2}{*}{ Outcome variables } & \multicolumn{3}{|c|}{ Positive framing } & \multicolumn{2}{|c|}{ Negative framing } & \multirow[t]{2}{*}{$\mathrm{p}$} & \multirow{2}{*}{\multicolumn{2}{|c|}{ Cohen's $d$}} \\
\hline & \multicolumn{2}{|c|}{$M(S D)$} & $n$ & $M(S D)$ & $n$ & & & \\
\hline Intention to participate (T1) & \multicolumn{2}{|c|}{$9.91(3.60)$} & 138 & $9.56(3.56)$ & 163 & 0.40 & & 0.10 \\
\hline Intention to participate (T2) & \multicolumn{2}{|c|}{$10.05(3.34)$} & 78 & $9.30(3.60)$ & 86 & 0.16 & & 0.22 \\
\hline Perceived susceptibility (T1) & \multicolumn{2}{|c|}{$3.60(1.44)$} & 138 & $3.72(1.53)$ & 163 & 0.48 & & 0.08 \\
\hline Perceived susceptibility (T2) & \multicolumn{2}{|c|}{$3.49(1.45)$} & 78 & $3.74(1.67)$ & 86 & 0.30 & & 0.16 \\
\hline \multirow[t]{2}{*}{ Outcome variables } & \multicolumn{3}{|c|}{ No narrative information } & \multicolumn{2}{|c|}{ Narrative information } & \multirow[t]{2}{*}{$p$} & \multirow{2}{*}{\multicolumn{2}{|c|}{ Cohen's $d$}} \\
\hline & \multicolumn{2}{|c|}{$M(S D)$} & $n$ & $M(S D)$ & $n$ & & & \\
\hline Intention to participate (T1) & \multicolumn{2}{|c|}{$9.84(3.62)$} & 156 & $9.59(3.54)$ & 145 & \multicolumn{2}{|l|}{0.55} & 0.07 \\
\hline Intention to participate (T2) & \multicolumn{2}{|c|}{$9.64(3.61)$} & 76 & $9.67(3.40)$ & 88 & \multicolumn{2}{|l|}{0.94} & 0.01 \\
\hline Perceived severity (T1) & \multicolumn{2}{|c|}{$17.28(2.79)$} & 156 & $17.10(2.73)$ & 145 & \multicolumn{2}{|l|}{0.59} & 0.07 \\
\hline Perceived severity (T2) & \multicolumn{2}{|c|}{$17.68(2.40)$} & 76 & $17.16(2.88)$ & 88 & \multicolumn{2}{|l|}{0.21} & 0.20 \\
\hline \multirow[t]{2}{*}{ Outcome variables } & \multicolumn{2}{|c|}{ Group 1} & Group 2 & \multicolumn{2}{|c|}{ Group 3} & \multicolumn{2}{|c|}{ Group 4} & $\mathrm{p}$ \\
\hline & $M(S D)$ & $n$ & $M(S D)$ & $M(S D)$ & $\mathrm{n}$ & $M(S D)$ & $\mathrm{n}$ & \\
\hline Intention to participate (T1) & $9.97(3.76)$ & 71 & $9.84(3.45)$ & $9.73(3.52)$ & 85 & $9.37(3.61)$ & 78 & 0.79 \\
\hline Intention to participate (T2) & $10.32(3.66)$ & 34 & $9.84(3.10)$ & $9.10(3.52)$ & 42 & $9.50(3.71)$ & 44 & 0.42 \\
\hline
\end{tabular}

(Group 1 = positive framing and no narrative information; Group 2 = positive framing and narrative information; Group 3 =negative framing and no narrative information; Group 4 =negative framing and narrative information).

between intention and actual participation becomes longer. ${ }^{25}$ This research had only an exploratory purpose as actual participation in ECS could not be measured at this stage. Respondents were recruited via an existing panel of an international company specialized in sampling. Therefore we cannot establish whether our sample is representative of the target population that is getting the offer of ECS in the future. Other limitations were that some scales were selfconstructed, had low internal consistency or were measured with only one item, resulting in lower validity of those scales. Finally, there were many drop-outs in the follow-up measurement. However, despite these drop-outs, the effect of the manipulations remained the same for both measurements.

In our study respondents had to imagine a hypothetical situation, as ECS as regular care is yet unavailable. To facilitate the implementation of ECS in a responsible way in this relatively new and unknown field, such exploratory research has to be done in advance. After finishing preparatory studies like this one, our research group has recently started an implementation study in which 4230 women of reproductive age from the Northern Netherlands were informed by their general practitioner about the option of ECS. Participating women could ask for further counselling and couple screening through their general practitioner if they were planning pregnancy.

In conclusion, this research clarifies which factors are most related to intended participation in ECS. Message framing and narrative information could inform the general public about ECS without influencing their intended participation. As perceived benefits and a positive attitude were the strongest explanatory factors, future research should study if the importance of these factors can be replicated when other factors are included and when actual participation is measured instead of intended participation. Better and more personalized information about ECS will make it easier for prospective parents to form attitudes about the test that correspond to their own norms and values.

\section{CONFLICT OF INTEREST}

The authors declare no conflict of interest.

\section{ACKNOWLEDGEMENTS}

We thank Kate McIntyre for editing our manuscript.

1 Henneman L, Borry P, Chokoshvili D et al: Responsible implementation of expanded carrier screening. Eur J Hum Genet 2016; 24: e1-e12.

2 van der Hout S, Holtkamp KC, Henneman L, de Wert G, Dondorp WJ: Advantages of expanded universal carrier screening: what is at stake? Eur J Hum Genet 2017; 25: 17-21.

3 Plantinga M, Birnie E, Kaplan S et al: Population-based preconception carrier screening: How do potential users view a test for 50 severe autosomal recessive diseases? Eur J Hum Genet 2016; 24: 1417-1423.

4 Damman OC, Bogaerts NM, van Dongen D, Timmermans DR: Barriers in using cardiometabolic risk information among consumers with low health literacy. $\mathrm{Br} J$ Health Psychol 2016; 21: 135-156.

5 Scherer LD, Ubel PA, McClure J et al: Belief in numbers: When and why women disbelieve tailored breast cancer risk statistics. Patient Educ Couns 2013; 92. 253-259.

6 Fagerlin A, Zikmund-Fisher BJ, Ubel PA: Helping patients decide: ten steps to better risk communication. J Nat/ Cancer Inst 2011; 103: 1436-1443.

7 Edwards A, Gray J, Clarke A et al: Interventions to improve risk communication in clinical genetics: systematic review. Patient Educ Couns 2008; 71: 4-25.

8 Sheeran P, Conner M, Norman P: Can the theory of planned behavior explain patterns of health behavior change? Health Psychol 2001; 20: 12-19.

9 Janz NK, Becker MH: The Health Believe Model: a decade later. Health Educ Q 1984; 11: $1-47$.

10 Ajzen I: The theory of planned behavior. Organ Behav Hum Decis Process 1991; 50 : 179-211.

11 Lakeman P, Plass AM, Henneman L, Bezemer PD, Cornel MC, ten Kate LP: Preconceptional ancestry-based carrier couple screening for cystic fibrosis and haemoglobinopathies: What determines the intention to participate or not and actual participation? Eur J Hum Genet 2009; 17: 999-1009.

12 Chen LS, Goodson P: Factors affecting decisions to accept or decline cystic fibrosis carrier testing/screening: a theory-guided systematic review. Genet Med 2007; 9: 442-450.

13 Ioannou L, McClaren BJ, Massie J et al: Population-based carrier screening for cystic fibrosis: a systematic review of 23 years of research. Genet Med 2014; 16 : 207-216.

14 Holtkamp KC, Mathijssen IB, Lakeman P et al: Factors for successful implementation of population-based expanded carrier screening: learning from existing initiatives. Eur J Public Health 2017; 27: 372-377.

15 Crombag NM, Schielen PC, Hukkelhoven CW et al: Determinants of first trimester combined test participation within central region of the Netherlands. Prenat Diagn 2015; 35: 486-492.

16 Adeola Animasahun B, Nwodo U, Njokanma OF: Prenatal screening for sickle cell anemia: awareness among health professionals and medical students at the Lagos 
University Teaching Hospital and the concept of prevention by termination. J Pediatr Hematol Oncol 2012; 34: 252-256.

17 Levin IP, Schneider SL, Gaeth GJ: All frames are not created equal: a typology and critical analysis of framing effects. Organ Behav Hum Decis Process 1998; 76: 149-188.

18 Tversky A, Kahneman D: The framing of decisions and the psychology of choice. Science $1981 ; 211: 453-458$.

19 Akl EA, Oxman AD, Herrin J et al: Framing of health information messages. Cochrane Database Syst Rev 2011; 12: 1-84.

20 Winterbottom A, Bekker HL, Conner M, Mooney A: Does narrative information bias individual's decision making? A systematic review. Soc Sci Med 2008; 67: 2079-2088.
21 Bekker HL, Winterbottom AE, Butow $\mathrm{P}$ et al: Do personal stories make patient decision aids more effective? A critical review of theory and evidence. BMC Med Inform Decis Mak 2013; 13(Suppl 2): S9.

22 Survey Sampling International. Survey sampling international. http://www.surveysampling.nl.

23 van den Berg M, Timmermans DR, Knol DL et al: Understanding pregnant women's decision making concerning prenatal screening. Health Psychol 2008; 27: 430-437.

24 Henneman L, Bramsen I, van der Ploeg HM et al: Participation in preconceptional carrier couple screening: Characteristics, attitudes, and knowledge of both partners. J Med Genet 2001; 38: 695-703.

25 Webb TL, Sheeran P: Does changing behavioral intentions engender behavior change? A meta-analysis of the experimental evidence. Psychol Bull 2006; 132: 249-268.

Supplementary Information accompanies this paper on European Journal of Human Genetics website (http://www.nature.com/ejhg) 